\title{
A DEGRADAÇÃO DA BACIA DO RIO PARAÍBA DO SUL
}

\author{
Daniel I. De Souza Jr. ${ }^{1}$
}

Resumo: Devido ao aumento pelos recursos hídricos causado pela expansão demográfica na Bacia do Rio Paraíba do Sul, as prefeituras locais e seus serviços autônomos, bem como as empresas estaduais de saneamento, procuram atender a esse aumento de demanda através apenas do acréscimo do fornecimento de água, sem a mesma contrapartida em relação ao esgotamento sanitário. A pergunta que se faz é a de quem seria a responsabilidade pelo esgotamento sanitário nos Estados. As empresas estaduais de saneamento do Rio de Janeiro e de Minas Gerais, respectivamente a CEDAE e a COPASA, possuem uma participação desprezível, praticamente inexistente, no esgotamento sanitário desses Estados. Um dos problemas para que essas empresas estaduais de saneamento possam reunir condições para a realização dessa tarefa é o preço cobrado pela prestação desse serviço: as tarifas praticadas são muito baixas ou mesmo simbólicas, e isso quando ainda existem. No Estado de São Paulo, a SABEP é responsável pelo esgotamento sanitário de cerca de $40 \%$ dos municípios da Bacia paulista. O volume de recursos obtido por essa empresa é bem significativo quando comparado com os aferidos tanto para a CEDAE como para a COPASA. Por outro lado, quando a responsabilidade está voltada para as prefeituras ou serviços autônomos, com raras exceções, nos três Estados analisados o que se faz na grande maioria dos casos é uma simples coleta, ou então o uso das redes de drenagem fluvial para o afastamento dos tributários domésticos. O objetivo desse estudo é o de mostrar alguns dos principais problemas relacionados ao esgotamento sanitário na Bacia do Rio Paraíba do Sul.

Palavras-chave: Recursos Hídricos, Fontes de Degradação, Esgotamento Sanitário, Bacia do Rio Paraíba do Sul.

Abstract: There has been an increased demand for water resources due to the population expansion in the Paraíba do Sul River Basin. Due to this increase, the city governments and their auxiliary services, as well as the state sanitation companies, have tried to cope with this situation by furnishing water with no thought given to sanitary exhaustion. The question of who is responsible for sanitary exhaustion in each state is up in the air. The state sanitation companies for Rio de Janeiro, CEDAE, and Minas Gerais, COPASA, have practically no involvement in the sanitary exhaustion in their jurisdictions. One of the problems that these companies face is the lack of money caused by the low rates that these companies are allowed to charge for this service. The rates are low, merely symbolic or non existent. The São Paulo sanitation company, SABEP, is responsible for the sanitation exhaustion of more than $40 \%$ of the commodities in the Paulista Basin. SABEP receives much more money then CEDAE and COPASA together. As the state sanitation companies are unable to function in the treatment of sanitary exhaustion, this burden has been passed on to the city governments, who, in their turn, with few exceptions, are allowing the collection of raw sewage, with no treatment, to be drained away in the fluvial drainages. In this work, we will address some of major problems related to the Paraíba do Sul River Basin.

Key-words: Water resources, Degradation Sources, Sanitary Exhaustion, Paraíba do Sul River Basin.

\footnotetext{
${ }^{1}$ Universidade Federal. Fluminense, Dept. de Eng Civil, Programa de Doutorado / Universidade. Estadual do Norte Fluminense, Laboratório de Engenharia de Produção. disj44@hotmail.com 


\section{A BACIA DO RIO PARAÍBA DO SUL}

O Rio Paraíba do Sul é formado pela confluência dos rios Paraitinga e Paraibuna, na serra da Bocaina (MG), e deságua no norte fluminense, no município de São João da Barra, percorrendo uma extensão aproximada de $1.150 \mathrm{~km}$ (Jornal da ASEAC, 2001). A Bacia do Rio Paraíba do Sul está situada na região Sudeste do Brasil e ocupa aproximadamente $\quad 55.400 \quad \mathrm{~km} 2$, compreendendo os estados de São Paulo (13.500 km2), Rio de Janeiro (21.000 km2) e Minas Gerais (20.900 km2). A Bacia abrange 180 municípios, com uma população total de 5.588 .237 , 88,79\% da qual vive nas áreas urbanas.

Apesar da Bacia do Rio Paraíba do Sul ser fortemente urbanizada e industrializada, o principal usuário da água, em termos de volume de captação, é o setor de irrigação $(49,73 \mathrm{~m} 3 / \mathrm{s})$, se não se considerarem as transposições dos rios Paraíba do Sul (160 m3/s) e Piraí (20 m3/s) para a Região Metropolitana do Rio de Janeiro (RMRJ). O abastecimento urbano utiliza cerca de 16,50 m3/s enquanto que o setor industrial capta $13,65 \mathrm{~m} 3 / \mathrm{s}$, superando somente o setor de pecuária, cujo consumo é inferior a 4 m3/s (Gruben, Anna; Lopes, P. Duarte; Formiga-Johnsson, R. Maria.).

Nas últimas décadas houve um aumento substancial no abastecimento de água da população urbana situada na Bacia do Paraíba do Sul. Devido a esse aumento pelos recursos hídricos causado pela expansão demográfica na região da bacia, as prefeituras locais e seus serviços autônomos, bem como as empresas estaduais de saneamento, procuraram atender a esse aumento de demanda através do acréscimo do fornecimento de água de um modo quase que automático, sem a mesma contrapartida em relação ao esgotamento sanitário. Desse modo, esse aumento por recursos hídricos não foi acompanhado pela correspondência de coleta de esgotos e de seu tratamento, causando assim uma deterioração da qualidade das águas fornecidas à população local.

ENGEVISTA, v. 6, n. 3, p. 99-105, dezembro 2004
Como resultante, atualmente a poluição doméstica é considerada como a mais crítica da bacia.

Existe no momento um número bem elevado e diversificado de indústrias situadas na região da bacia. Podemos citar como exemplo, indústrias do tipo química e metalúrgica, siderúrgica, produtoras de papel, mineração, usinas de álcool e açúcar, empresas têxteis, de bebidas, etc. Devido a um aumento nos últimos anos da fiscalização ambiental, muitas dessas empresas instalaram sistemas de tratamento de efluentes, mas sem eliminar, no entanto, o evento de lançamento de cargas tóxicas nos rios.

Um outro significativo elemento poluidor da Bacia do Rio Paraíba do Sul é a indústria da pecuária. Essa atividade econômica é a que ocupa a maior extensão na bacia. Cerca de $70 \%$ das terras estão cobertos por campos/pastagens, em sua maioria deterioradas pelas reiteradas queimadas e pelo pisoteio do gado. Por sua vez, a agricultura ocupa uma área bem menor, de cerca de $10 \%$, apesar de representar uma das mais importantes fontes de poluição do solo e da água devido ao uso descontrolado de fertilizantes e agrotóxicos (Gruben, Anna; Lopes, P. Duarte; Formiga-Johnsson, R. Maria).

Apesar da elevada importância do Rio Paraíba do Sul, a preservação e a despoluição de sua Bacia não têm recebido, já há muito tempo, a prioridade devida por parte do Poder Público estadual. O Rio Paraíba do Sul se encontra no momento assoreado, poluído e, embora o assunto seja debatido há anos, pouco ou quase nada foi efetivamente feito para tentar garantir em longo prazo a sua sobrevivência (RIPS Rede de Informações do Paraíba do Sul, 2005).

No Estado do Rio de Janeiro, devido principalmente à falta de recursos, algumas poucas prefeituras tem tido condição de atacar de frente esse problema de poluição, especialmente em relação à poluição doméstica e ao tratamento dos esgotos coletados. Com os recursos oriundos dos "royalties" do petróleo, a prefeitura da cidade de 
Campos dos Goytacazes vem nos últimos cinco anos desenvolvendo um trabalho efetivo visando à solução desse problema.

O grau de importância e de dependência que o Estado do Rio de Janeiro e a Região Metropolitana da cidade do Rio de Janeiro têm em relação à Bacia hidrográfica do Rio Paraíba do Sul é bem maior que se possa, a princípio, imaginar. Para que se tenha uma idéia, esse Rio representa o maior recurso hídrico do Estado e abastece de água potável cerca de 10 milhões de pessoas, $80 \%$ da população da capital e das cidades da Região Metropolitana do Rio de Janeiro. (Portugal, Gil, 1996).

Essa água que abastece a Região Metropolitana do Rio de Janeiro chega às torneiras do carioca através da transposição da Serra do Mar pelo Rio Paraíba do Sul que, após a geração de energia elétrica nas hidrelétricas Nilo Peçanha, Fontes e Pereira Passos, dá origem ao Rio Guandu. Esse rio, por sua vez, forma uma sub-bacia que recebe contribuições dos rios que margeiam a Baixada Fluminense. A criação desse Rio artificial se constituiu em uma obra de engenharia relevante e proporcionou a instalação de uma tomada de água que, hoje, possui a capacidade para retirar do Rio Guandu uma vazão de até $80 \mathrm{~m}^{3} /$ segundo (Jornal da ASEAC, 2001). E como recebe águas do Rio Paraíba do Sul, a sub-bacia do Rio Guandu se encontra também bastante poluída, o que pode trazer conseqüências drásticas ao abastecimento da Região Metropolitana do Estado nos próximos anos.

Entre as grandes obras que deverão ser iniciadas em 2005 no Rio Paraíba do Sul podemos destacar a Usina Hidrelétrica de Simplício, município situado na região Centro-Sul fluminense. A ANEEL (Agência Nacional de Energia Elétrica) deverá realizar em Abril próximo um leilão para a concessão dessa obra. A companhia Furnas deverá ser uma das fortes candidatas a ganhar essa concessão, pois possui praticamente pronto um projeto viável que envolve tanto o aspecto ambiental como o financeiro.

Uma das novidades desse projeto é que, ao invés de se construir uma grande barragem com as implicações ecológicas que essa barragem poderia causar como a inundação das terras da região, serão construídos canais indutores, evitando-se assim que as populações ribeirinhas sejam atingidas. Em um desses canais indutores deverá ser construída uma pequena central hidrelétrica. $\mathrm{O}$ curso do Rio Paraíba do Sul será temporariamente desviado apenas durante a fase de construção dos canais indutores, pois já existe no local de construção da futura hidrelétrica um canteiro de obras proveniente de um antigo projeto para essa hidrelétrica feito há 18 anos atrás (RIPS - Rede de Informações do Paraíba do Sul, 2005).

\section{PRINCIPAIS FONTES DE DEGRADAÇÃO DA BACIA DO RIO PARAÍBA DO SUL}

Dentre as principais fontes de degradação existentes na Bacia do Rio Paraíba do Sul, pode-se citar:

a. Degradação por Disposição de Resíduos Sólidos.

A situação da disposição final dos resíduos sólidos é extremamente grave se forem consideradas as condições e os efeitos dessa disposição (Vale Verde Associação de Defesa do Meio Ambiente, 2004). Talvez o mais relevante problema esteja relacionado ao favorecimento de infiltrações e contaminações do lençol freático quando da liberação de chorume.

O chorume é um líquido escuro contendo alta carga poluidora, o que pode ocasionar diversos efeitos sobre o meio ambiente. O potencial de impacto deste efluente está relacionado com a alta concentração de matéria orgânica, reduzida biodegradabilidade, presença de metais pesados e de substâncias recalcitrantes. Diversos fatores contribuem para que o resíduo da decomposição do lixo (chorume) seja complexo e apresente significativas 
variações em sua composição. Dentre as mais importantes contam-se: dinâmica de decomposição ao longo do tempo, variações na forma de operação do aterro sanitário, na composição dos resíduos depositados, no volume de chuvas e outras alterações climáticas (Tecnotrater, 2005).

Outro problema diz respeito às condições insalubres dos "lixões", tendo como conseqüência a instalação e a proliferação de agentes causadores de doenças, além dos criadouros de insetos que trazem incômodos à população. Além disso, um mal acondicionamento do lixo pode favorecer a que o mesmo seja transportado por chuvas para os corpos de água, aumentando a contaminação desses corpos, e também entupindo a rede de drenagem urbana, tendo como resultado, enchentes localizadas.

\section{b. Expansão Urbana.}

Os recursos hídricos da Bacia do Rio Paraíba do Sul possuem como maior fonte poluidora o baixo tratamento dos esgotos coletados. Devido ao aumento pelos recursos hídricos causado pela expansão demográfica na Bacia do Rio Paraíba do Sul, as prefeituras locais e seus serviços autônomos, bem como as empresas estaduais de saneamento, procuram atender a esse aumento de demanda através do acréscimo do fornecimento de água, de um modo quase que automático, sem a mesma contrapartida em relação ao esgotamento sanitário.

Uma conseqüência imediata da falta de uma abordagem séria sobre 0 esgotamento sanitário está relacionada ao baixo tratamento dos esgotos coletados. Para que se tenha uma melhor idéia do problema, as redes de coleta e afastamento de esgotos atendem no momento a aproximadamente $82 \%$ da população urbana do Estado de São Paulo, enquanto que o tratamento limitase a apenas $10,5 \%$ dessa população. No Estado do Rio de Janeiro esse atendimento é de aproximadamente $45 \%$ da população urbana, com o tratamento sendo oferecido a apenas $2 \%$ dessa ENGEVISTA, v. 6, n. 3, p. 99-105, dezembro 2004 população. O pior se verifica no Estado de Minas Gerais, no qual para um atendimento de aproximadamente $48,5 \%$ da população urbana, o tratamento limitase apenas a 1,2 \% dessa população.

Como conseqüência desses baixos índices de tratamento, os córregos ou cursos de água que cortam as áreas urbanas apresentam um elevado nível de poluição, tendo como resultado imediato o aparecimento e a propagação de doenças pelo meio hídrica.

A pergunta que se faz é a de quem seria realmente a responsabilidade pelo esgotamento sanitário nos Estados. As empresas estaduais de saneamento do Rio de Janeiro e de Minas Gerais, respectivamente a CEDAE e a COPASA, possuem uma participação desprezível, praticamente inexistente, no esgotamento sanitário desses Estados. Um dos problemas para que essas empresas estaduais de saneamento possam reunir condições para a realização dessa tarefa é o preço cobrado pela prestação desse serviço: as tarifas praticadas são muito baixas ou mesmo simbólicas, e isso quando ainda existem.

No Estado de São Paulo, a SABEP é responsável pelo esgotamento sanitário de cerca de $40 \%$ dos municípios da Bacia paulista, sendo que o volume de recursos obtido por essa empresa é bem significativo quando comparado com os aferidos tanto para a CEDAE como para a COPASA.

Por outro lado, quando a responsabilidade está voltada para as prefeituras ou serviços autônomos, com raras exceções, nos três Estados analisados o que se faz na grande maioria dos casos é uma simples coleta, ou então o uso das redes de drenagem fluvial para o afastamento dos tributários domésticos.

c. Degradação em corpos hídricos por processos de assoreamento e instabilidade.

A degradação dos corpos hídricos por assoreamento inicia-se com os processos de erosão natural nas encostas, sendo em geral agravados por desmatamentos, cortes, aterros, exposição de solos. Além do assoreamento e sedimentos em 
suspensão, o Rio Paraíba do Sul está também sujeito a profundas alterações em seu regime hidráulico e na produção de sedimentos, devido à prática de encurtamento do canal pelos cortes de meandros, aumento da declividade do canal e pela intensa atividade de extração de areia em seu leito e várzeas.

Essas alterações produzem instabilidades, cujos efeitos mais imediatos se relacionam com 0 rebaixamento generalizado das linhas de água ao longo do trecho onde se verifica uma maior extração de areia, diminuindo assim a seção de escoamento, afogamento da descarga dos afluentes, tendo como conseqüência maiores transbordamentos, e, portanto, maiores e inesperadas enchentes em áreas ribeirinhas (Vale Verde - Associação de Defesa do Meio Ambiente, 2004).

d. Degradação por Atividades de Mineração.

Na Bacia do Rio Paraíba do Sul a extração de areia para aplicação em várias indústrias, principalmente a da construção civil, é seguramente o maior fator de degradação ambiental pelo extrativismo mineral. Os efeitos nefastos da extração da areia no meio ambiente acarretam conseqüências altamente detrimentais para o ambiente aquático e ribeirinho, e em muitas das vezes essas conseqüências são irreversíveis.

A extração de areia de leitos de rios ou em cavas submersas em áreas da várzea tem como resultante a poluição das águas, causada pela agitação de sedimentos finos (argilas e silte), pela presença nessas areias de combustíveis e óleos lubrificantes, e pelos efluentes sanitários das instalações administrativas. Nas encostas da Bacia, o método preferido de extração de areia é do de desmonte hidráulico, o qual utiliza processo de jateamento com água, o que favorece a erosão, o assoreamento de cursos de água, os desmatamentos, com a conseqüente destruição das matas e florestas da região, a perda de solo orgânico, etc.

Devido à conhecida escassez de areia no leito dos rios e também pela facilidade ENGEVISTA, v. 6, n. 3, p. 99-105, dezembro 2004 de operação, na Bacia do Rio Paraíba do Sul o método mais utilizado de extração de areia é o de mineração por escavação. Esse método é responsável por cerca de $80 \%$ de toda a areia extraída na região. Evidentemente, as principais conseqüências desse procedimento estão relacionadas com a perda de solo, a erosão do material de decapagem quando estocados de forma inadequada, a erosão da frente da lavra e o abandono de grandes cavas ao término da atividade, impedindo o uso futuro do solo e gerando criadouros de causadores de doenças e incômodos à população (Vale Verde Associação de Defesa do Meio Ambiente, 2004).

Além da areia, a argila, muito empregada em olarias situadas na região da Bacia, se constitui em um fator significativo de degradação. A argila é também explorada no Vale, principalmente em Jacareí (3 áreas), Taubaté (3 áreas), e Cachoeira Paulista (2 áreas). A turfa é explorada em São José dos Campos. Um outro elemento causador de degradação ambiental nessa região é o granito ornamental, o que ocorre principalmente nas regiões de Santa Branca (cava), Igaratá (fogo), Aparecida (fogo), Guaratinguetá (fogo), Roseira(fogo), Cachoeira Paulista (fogo) e Queluz (fogo). É explorado também o gnaisse em Taubaté; a bauxita em duas grandes áreas em Lavrinhas (fogo/mecânica) com represas de contenção; e quartzito em uma área em Queluz (Vale Verde - Associação de Defesa do Meio Ambiente, 2004).

\section{e. Inundações em Áreas Urbanizadas}

Um dos problemas causados pela ocupação indevida de áreas ribeirinhas, naturalmente frágeis, está relacionado com a perda da qualidade ambiental, resultando em uma baixa qualidade de vida para as populações que as habitam. Muitas dessas áreas ribeirinhas estão sujeitas às inundações periódicas de rios e córregos que cortam a região. Como conseqüência imediata dessas inundações, além do risco de perda de vidas humanas e de prejuízo material, existe um agravamento das condições 
sanitárias, as quais se tornam insalubres, colocando assim em grave risco a saúde pública.

Durante a temporada chuvosa, existe na Bacia do Rio Paraíba do Sul, nas áreas baixas das cidades de Campos dos Goytacazes, Lorena, Cachoeira Paulista, Guaratinguetá, Aparecida, Jacareí e São José dos Campos, uma probabilidade muito significativa para a ocorrência do fenômeno da inundação.

Em Campos dos Goytacazes, no Norte Fluminense, o Rio Paraíba do Sul costuma ter seu volume aumentado por chuvas que caem nas cabeceiras de afluentes como os Rios Pomba e Muriaé, em Minas Gerais. O Paraíba do Sul absorve também as chuvas que caem em São Paulo. As principais localidades afetadas em Campos são as de Três Vendas e Itereré (RIPS - Rede de Informações do Paraíba do Sul, 2004). Nos últimos anos algumas das prefeituras da região Norte-Noroeste Fluminense vem procurando minimizar esse problema, através da remoção permanente de moradores das regiões de risco, buscando relocar essas famílias em áreas mais protegidas contra a inundação, além de promover um trabalho constante de limpeza das ruas e dos bueiros, mesmo sem contar, na maioria das vezes, com a mínima ajuda do poder estadual.

As cheias de Lorena e Guaratinguetá já estão parcialmente controladas por barragens nos ribeirões Santa Lucrécia e Taboão, e Motas, respectivamente. As várzeas do Rio Paraíba do Sul, situadas entre os municípios de Jacareí e Cachoeira Paulista, estão freqüentemente sujeitas a inundações. Essas inundações estão atualmente atenuadas pela implantação de obras hidráulicas na bacia, como os reservatórios de cabeceira Paraibuna/Paraitinga e Jaguari; pela retificação do leito entre Caçapava e Cachoeira Paulista e pela construção de diques marginais, com proteção de 18.500 hectares dos 34.000 hectares sujeitos às inundações (Vale Verde Associação de Defesa do Meio Ambiente, 2004).

\section{CONCLUSÕES SOBRE A DEGRADAÇÃO DA BACIA DO RIO PARAÍBA DO SUL}

Os principais problemas a serem enfrentados para uma tentativa de recuperação efetiva da Bacia do Rio Paraíba do Sul podem ser resumidos nos seguintes pontos (Vale Verde Associação de Defesa do Meio Ambiente, 2004):

a. Uma maior dificuldade de recuperação da qualidade da água nos trechos urbanos dos rios e a jusante das cidades, ou seja, o sentido em que correm as águas de uma corrente fluvial, pela inexistência ou deficiência na coleta, afastamento e tratamento dos esgotos domésticos.

b. Como conseqüência da baixa fertilidade e ao elevado nível de degradação das terras, principalmente nas várzeas da Bacia do Rio Paraíba do Sul sujeitas ao efeito nocivo da mineração e da pecuária, torna-se bastante problemática e improvável uma regeneração natural dos solos e, por conseqüência, das florestas.

c. Um aumento provável das erosões e assoreamentos causados por uso inadequado do solo, conseqüência do desconhecimento de métodos apropriados para a conservação dos mesmos e de manejo de florestas.

d. O desmatamento das áreas próximas as cabeceiras de rios e ribeirões aumenta significativamente o risco de diminuição da produção de água na Bacia do Rio Paraíba do Sul, trazendo como conseqüência uma diminuição acentuada na disponibilidade hídrica.

De um modo geral, ações nocivas ao meio ambiente, tais como a devastação das florestas com um alto índice de substituição dos ambientes naturais; cortes e desmontes em encostas para instalação de edificações e sistema viário; mutilações nas várzeas e leito do Rio Paraíba do Sul pela extração de areia e para controle de enchentes locais; comprometimento da qualidade da água dos rios pela poluição doméstica e industrial, cargas difusas e assoreamentos; geração de várias toneladas diárias de resíduos sólidos sem 
destinação final adequada; concentração populacional contribuindo para a redução da qualidade de vida e para aumento de impermeabilizações, aumentando a contribuição às enchentes urbanas; risco aos ecossistemas ainda presentes mesmo em áreas legalmente protegidas; entre outras, são algumas das ocorrências atuais que possuem uma elevada probabilidade de agravamento caso medidas sérias e efetivas de controle e prevenção dos problemas relativos à Bacia do Rio Paraíba do Sul, acima relacionados, não sejam tomadas de imediato (Vale Verde - Associação de Defesa do Meio Ambiente, 2004).

\section{BIBLIOGRAFIA}

Gruben, Anna; Lopes, P. Duarte; Formiga-Johnsson, R. Maria, 2005, Projeto Marca D’ Água. Bacia13 - Bacia do Paraíba do Sul (São Paulo, Rio de Janeiro e Minas Gerais)

http://www.marcadagua.org.br/

bacia13.htm

Jornal da ASEAC, 2001, Paraíba do Sul: um Rio no curso da morte. Informativo Mensal da Associação dos Empregados de Nível Universitário da CEDAE. Edição de Maio/Junho de 2001.

http://www.aseac.com.br/jorn34_9.htm
Portugal, Gil, 1996. Rio Paraíba do Sul ou Baía da Guanabara?

http://www.gpca.com.br/Gil/art105.htm

RIPS, 2005, Rede de Informações do Paraíba do Sul, 10 de Janeiro de 2005.

http://www.ana.gov.br/paraibadosul/

Atualidade.htm

RIPS, 2004, Rede de Informações do Paraíba do Sul, 27 de Dezembro de 2004.

http://www.ana.gov.br/paraibadosul/

Atualidade.htm

Tecnotrater, 2005, Grupo de Desenvolvimento de Técnicas Avançadas para o Tratamento de Resíduos. Coordenador: Prof. Patrício PeraltaZamora. Universidade Federal do Paraná, Departamento de Química.

http://bohr.quimica.ufpr.br/ tecnotrat/

chorume.htm

Vale Verde, 2004,Associação de Defesa do Meio Ambiente. Rio Paraíba do Sul. Dados fornecidos pelo Comitê de Bacias Hidrográficas - Rio Paraíba do Sul e Serra da Mantiqueira.

http://www.valeverde.org.br/html/

rio2.php\#a19 